\title{
Erratum: Khan, A.A., et al. Survival and Estimation of Direct Medical Costs of Hospitalized COVID-19 Patients in the Kingdom of Saudi Arabia (Short Title: COVID-19 Survival and Cost in Saudi Arabia). Int. J. Environ. Res. Public Health 2020, 17, 7458
}

\author{
Anas A. Khan ${ }^{1,+}\left(\mathbb{D}\right.$, Yazed AlRuthia ${ }^{2,3, *,+}\left(\mathbb{D}\right.$, Bander Balkhi ${ }^{2,3}$, Sultan M. Alghadeer ${ }^{2}$, \\ Mohamad-Hani Temsah ${ }^{4,5}$, Saqer M. Althunayyan ${ }^{6}\left(\mathbb{D}\right.$ and Yousef M. Alsofayan ${ }^{7}$ \\ 1 Department of Emergency Medicine, College of Medicine, King Saud University, Global Center for Mass \\ Gatherings Medicine, Ministry of Health, Riyadh 11451, Saudi Arabia; anaskhan@KSU.EDU.SA \\ 2 Department of Clinical Pharmacy, College of Pharmacy, King Saud University, P.O. Box 2454, Riyadh 11451, \\ Saudi Arabia; bbalkhi@KSU.EDU.SA (B.B.); salghadeer@ksu.edu.sa (S.M.A.) \\ 3 Pharmacoeconomics Research Unit, College of Pharmacy, King Saud University, P.O. Box 2454, Riyadh 11451, \\ Saudi Arabia \\ 4 College of Medicine, King Saud University, Riyadh 11451, Saudi Arabia; mtemsah@ksu.edu.sa \\ 5 Department of Pediatrics, King Saud University Medical City, King Saud University, Riyadh 11451, Saudi Arabia \\ 6 Department of Accident and Trauma, Prince Sultan Bin Abdulaziz College for Emergency Medical Services, \\ King Saud University, Riyadh 11451, Saudi Arabia; salthunayyan@KSU.EDU.SA \\ 7 Global Center for Mass Gatherings Medicine, Ministry of Health, Riyadh 11451, Saudi Arabia; \\ y-m-alsofayan@hotmail.com \\ * Correspondence: yazeed@ksu.edu.sa; Tel.: +966-114677483; Fax: +966-114677480 \\ + The first two authors contributed equally to this work.
}

Received: 8 December 2020; Accepted: 10 December 2020; Published: 17 December 2020

1. There is an error in the title. The correct title of the article [1] is "Survival and Estimation of Direct Medical Costs of Hospitalized COVID-19 Patients in the Kingdom of Saudi Arabia". We apologize for this error and state that the scientific conclusions are unaffected. The original article has been updated.

2. There is a typo mistake in the abstract's conclusion where "is" which follows "represents" should be deleted so that the sentence can be grammatically correct, as highlighted in the following text: "Conclusion: The high hospitalization costs for COVID-19 patients represents is a significant public health challenge. Efficient allocation of healthcare resources cannot be emphasized enough."

The authors would like to apologize for any inconvenience caused to the readers by these changes. 


\section{Reference}

1. Khan, A.A.; AlRuthia, Y.; Balkhi, B.; Alghadeer, S.M.; Temsah, M.H.; Althunayyan, S.M.; Alsofayan, Y.M. Survival and Estimation of Direct Medical Costs of Hospitalized COVID-19 Patients in the Kingdom of Saudi Arabia (Short Title: COVID-19 Survival and Cost in Saudi Arabia). Int. J. Environ. Res. Public Health 2020, 17, 7458. [CrossRef] [PubMed]

Publisher's Note: MDPI stays neutral with regard to jurisdictional claims in published maps and institutional affiliations.

(C) 2020 by the authors. Licensee MDPI, Basel, Switzerland. This article is an open access article distributed under the terms and conditions of the Creative Commons Attribution (CC BY) license (http://creativecommons.org/licenses/by/4.0/). 